\title{
Centennial records of lead contamination in northern Atlantic bivalves (Arctica islandica)
}

\author{
Jacqueline Krause-Nehring $^{\mathrm{a}, *}$, Thomas Brey ${ }^{\mathrm{a}}$, Simon R. Thorrold ${ }^{\mathrm{b}}$ \\ a Alfred Wegener Institute for Polar and Marine Research, Am Handelshafen 12, 27570 Bremerhaven, Germany \\ ${ }^{\mathrm{b}}$ Woods Hole Oceanographic Institution, Biology Department MS 50, Woods Hole, MA 02543, USA
}

\section{A R T I C L E I N F O}

\section{Keywords:}

Arctica islandica

Bivalve

Bioarchive

Lead pollution

Temperate northern Atlantic

\begin{abstract}
A B S T R A C T
In the study, we establish centennial records of anthropogenic lead pollution at different locations in the North Atlantic (Iceland, USA, and Europe) by means of lead deposited in shells of the long-lived bivalve Arctica islandica. Due to local oceanographic and geological conditions we conclude that the lead concentrations in the Icelandic shell reflect natural influxes of lead into Icelandic waters. In comparison, the lead profile of the US shell is clearly driven by anthropogenic lead emissions transported from the continent to the ocean by westerly surface winds. Lead concentrations in the European North Sea shell, in contrast, are dominantly driven by local lead sources resulting in a much less conspicuous 1970 s gasoline lead peak. In conclusion, the lead profiles of the three shells are driven by different influxes of lead, and yet, all support the applicability of $\mathrm{Pb} / \mathrm{Ca}$ analyses of $A$. islandica shells to reconstruct location specific anthropogenic lead pollution.
\end{abstract}

(c) 2011 Elsevier Ltd. All rights reserved.

\section{Introduction}

Metals constitute significant pollutants of the marine environment, which are introduced into the seawater by gas exchange at the sea surface, fall out of particles, or by being scavenged from the air column via precipitation (Clark, 2001). Natural sources of metals in seawater include volcanic activity, wind-blown dust, erosion of ore-bearing rocks, and forest fires (Clark, 2001). In addition, metals mobilized by anthropogenic activities reach the oceans via atmospheric deposition, rivers, and direct discharges or dumping (Clark, 2001).

Lead has been a matter of great concern due to its harmful effects on human health and the sheer quantity released into the environment. Its ability to imitate biologically important metals and to damage membranes determines the toxicity of lead (Company et al., 2008). As a neurotoxin lead may impair the normal neurological development of children even at low exposure levels and increase the risk of cardiovascular diseases and renal deficiencies in adults (Von Storch et al., 2003).

Human activity has changed the intensity of natural biogeochemical fluxes of lead (Bashkin, 2002). The history of lead use goes back to the times of the Egyptians and Babylonians (Bashkin, 2002). Also during the Roman Era lead was used extensively for the water supply system (Harrison and Laxen, 1981). However, the

\footnotetext{
* Corresponding author. Tel.: +49 47148312030.

E-mail address: jacqueline.krause-nehring@awi.de (J. Krause-Nehring).
}

first mayor increase in the deposition rate of lead coincides with the beginning of the industrial revolution in the middle of the 18th century (Clark, 2001). The second major increase in the flux of elemental lead into the ocean occurred between 1930 and 1970 as a consequence of the introduction of leaded gasoline with enhanced anti-knock properties (Boyle et al., 1986; Harrison and Laxen, 1981). Starting in the 1970s the use of lead alkyl additives decreased both in Europe and the USA, resulting in a drop of the environmental lead concentrations (Lazareth et al., 2000; Von Storch et al., 2003).

Most of the anthropogenic lead is being mobilized by refining of ores, accelerated soil erosion, and fossil fuel or leaded gasoline burning during which lead is injected into the atmosphere in the form of an aerosol (Libes, 1992). Upon deposition of lead in the surface ocean, the metal is converted into soluble form ( $\mathrm{Wu}$ and Boyle, 1997). The main forms of occurrence of dissolved lead include carbonate, hydroxide, and chloride complexes (Libes, 1992). According to Veron et al. (1987) the residence time of lead in surface waters is less than five years; the metal is removed by adsorption onto sinking biological particles (Wu and Boyle, 1997). As a consequence of anthropogenic lead emissions, the lead contamination of the ocean increased dramatically after 1750 and again after 1950 , largely due to atmospheric deposition (Clark, 2001). At present, anthropogenic emissions account for the majority of lead, which is transported to the atmosphere and rivers (Libes, 1992).

Monitoring of marine pollution is mandatory for successful management and protection of coastal and estuarine environments, which provide valuable environmental, economic, and recreational 